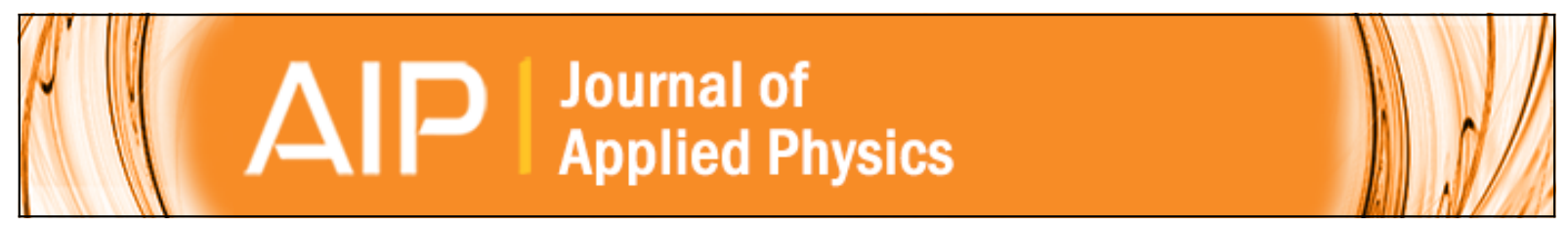

Nonresonant third-order nonlinearity of antimony glasses at telecom wavelengths

Luis A. Gómez, Cid B. de Araújo, D. N. Messias, L. Misoguti, S. C. Zilio, M. Nalin, and Y. Messaddeq

Citation: Journal of Applied Physics 100, 116105 (2006); doi: 10.1063/1.2388045

View online: http://dx.doi.org/10.1063/1.2388045

View Table of Contents: http://scitation.aip.org/content/aip/journal/jap/100/11?ver=pdfcov

Published by the AIP Publishing 


\title{
Nonresonant third-order nonlinearity of antimony glasses at telecom wavelengths
}

\author{
Luis A. Gómez and Cid B. de Araújo ${ }^{\text {a) }}$ \\ Departamento de Física, Universidade Federal de Pernambuco, 50670-901 Recife, Pernambuco, Brazil \\ D. N. Messias, L. Misoguti, and S. C. Zilio \\ Instituto de Física, Universidade de São Paulo, 13560-970 São Carlos, São Paulo, Brazil \\ M. Nalin and Y. Messaddeq \\ Instituto de Química, Universidade Estadual Paulista-UNESP, 14800-900 Araraquara, São Paulo, Brazil
}

(Received 11 August 2006; accepted 14 September 2006; published online 8 December 2006)

\begin{abstract}
We report measurements of the nonresonant nonlinear refractive index $n_{2}$ in antimony glasses at telecom wavelengths. The measurements were performed using the $Z$-scan technique with a $130 \mathrm{fs}$ pulsed laser operating at five wavelengths in the range of $1400-1600 \mathrm{~nm}$. Values of $n_{2}$ $\approx 10^{-15} \mathrm{~cm}^{2} / \mathrm{W}$ were measured and a negligible two-photon absorption coefficient $(<0.003$ $\mathrm{cm} / \mathrm{GW}$ ) was estimated for all glasses compositions. The samples present a good figure of merit for ultrafast all-optical switching. (C) 2006 American Institute of Physics. [DOI: 10.1063/1.2388045]
\end{abstract}

The implementation of all-optical switching requires materials with low linear and nonlinear losses, large Kerr nonlinearity, and ultrafast response. These requirements are usually expressed through two figures of merit (FOMs), $W$ $=n_{2} I / \alpha \lambda$ and $T=\alpha_{2} \lambda / n_{2}$, where $I$ is the incident light intensity, $\lambda$ is the light wavelength, $\alpha$ is the linear absorption coefficient, and $\alpha_{2}$ is the two-photon absorption coefficient. Materials that present $W>1$ and $T<1$ are good candidates for photonic switching applications. ${ }^{1}$

Transparent glasses with large nonlinearity are good candidates for all-optical switching. It is well known that the presence of atoms with large polarizability in the glass composition increases the nonlinear refractive index of a material, but the selection of an appropriate material is a challenge because normally large two-photon absorption is present when large $n_{2}$ is obtained. In such cases $T>1$ and the switching process loses efficiency.

Recently, compositions of antimony based glasses (AGs) were identified as appropriate for photonic applications. ${ }^{2-4}$ The AG compositions studied present glass transition temperature of $\approx 300{ }^{\circ} \mathrm{C}$, linear refractive index of $\approx 2$, large transmittance window from 380 to $2000 \mathrm{~nm}$, and high thermal stability. Although AG glasses have been discovered long time ago, ${ }^{5-7}$ only recently techniques were developed that allow the preparation of good optical quality samples. ${ }^{8-10}$ Up to the present time the characterization of the nonlinear (NL) optical absorption and NL refraction of AG has been limited to the wavelengths of 800 and $532 \mathrm{~nm}$. Large NL refractive index, low two-photon absorption coefficients, and ultrafast response (faster than $100 \mathrm{fs}$ ) at $800 \mathrm{~nm}$ were reported. ${ }^{3,4}$ On the other hand, photoinduced structural changes have been observed when exciting AG samples with blue and ultraviolet light. ${ }^{10}$

This paper reports on the measurements of the thirdorder nonlinearity of a compositional series of AG using the

\footnotetext{
a) Author to whom correspondence should be addressed; electronic mail: cid@df.ufpe.br
}

$Z$-scan technique from 1400 to $1600 \mathrm{~nm}$. Measurements of $n_{2}$ and evaluation of $\alpha_{2}$ were performed; values of FOM, $W$ and $T$, were obtained.

Three glass groups of different compositions were studied as presented in Table I. In the first group, four compositions of $\mathrm{Sb}_{2} \mathrm{O}_{3}-\mathrm{SbPO}_{4}$ glass were investigated. The second group was obtained by adding $\mathrm{PbO}$ to the composition of the first group. The third group consists of a binary antimony polyphosphate glass based on $\mathrm{Sb}_{2} \mathrm{O}_{3}-\mathrm{Sb}\left(\mathrm{PO}_{3}\right)_{3}$ and a sample to which $\mathrm{PbO}$ was added. The samples were prepared following the procedure described in Refs. 9 and 10. The glass transition temperature, the crystallization temperature, the structural organization of the samples, and the absorption spectra were given in a previous publication. ${ }^{10}$ Samples with thickness varying between 0.4 and $2.2 \mathrm{~mm}$ were used in the present experiments.

NL refraction and NL absorption were investigated using the $Z$-scan technique. ${ }^{11}$ The measurements were done using a tunable optical parametric amplifier (OPA) pumped with a Ti:Sapphire chirped pulse amplified (CPA-2001, CLARKMXR) system, delivering pulses of $130 \mathrm{fs}$ at $1 \mathrm{kHz}$ repetition rate. The OPA was tuned to operate in five wavelengths in the range 1400 to $1600 \mathrm{~nm}$. To implement the technique the laser beam was focused by a $12 \mathrm{~cm}$ focal distance lens.

TABLE I. Composition of the samples studied.

\begin{tabular}{ccc}
\hline \hline Group & Sample & Composition (\% mol) \\
\hline I & A & $70 \mathrm{Sb}_{2} \mathrm{O}_{3}-30 \mathrm{SbPO}_{4}$ \\
& $\mathrm{~B}$ & $60 \mathrm{Sb}_{2} \mathrm{O}_{3}-40 \mathrm{SbPO}_{4}$ \\
& $\mathrm{C}$ & $50 \mathrm{Sb}_{2} \mathrm{O}_{3}-50 \mathrm{SbPO}_{4}$ \\
& $\mathrm{D}$ & $40 \mathrm{Sb}_{2} \mathrm{O}_{3}-60 \mathrm{SbPO}_{4}$ \\
II & E & $50 \mathrm{Sb}_{2} \mathrm{O}_{3}-40 \mathrm{SbPO}_{4}-10 \mathrm{PbO}$ \\
& F & $30 \mathrm{Sb}_{2} \mathrm{O}_{3}-50 \mathrm{SbPO}_{4}-20 \mathrm{PbO}$ \\
III & $\mathrm{G}$ & $70 \mathrm{Sb}_{2} \mathrm{O}_{3}-30 \mathrm{Sb}^{\mathrm{P}}\left(\mathrm{PO}_{3}\right)_{3}$ \\
& $\mathrm{H}$ & $70 \mathrm{Sb}_{2} \mathrm{O}_{3}-20 \mathrm{Sb}\left(\mathrm{PO}_{3}\right)_{3}-10 \mathrm{PbO}$ \\
\hline \hline
\end{tabular}



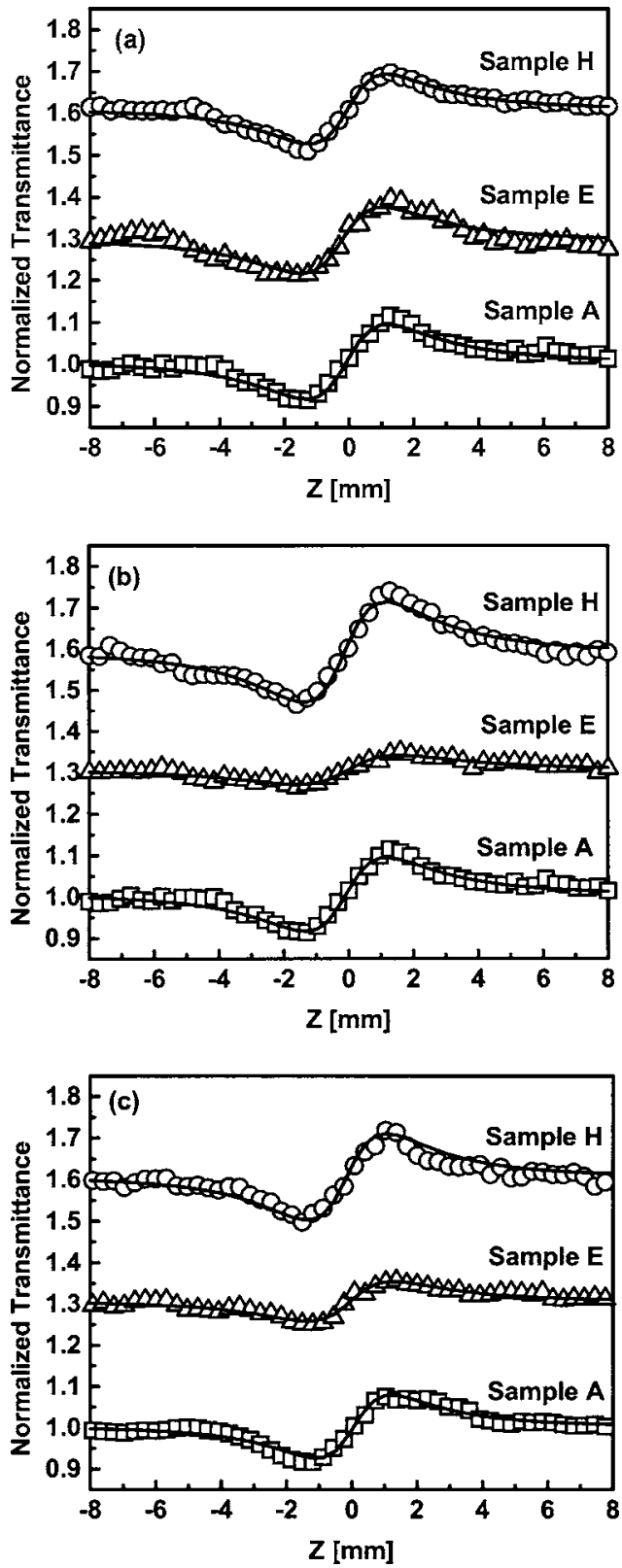

FIG. 1. Closed-aperture Z-scan traces at (a) $1400 \mathrm{~nm}$, (b) $1500 \mathrm{~nm}$, and (c) $1600 \mathrm{~nm}$. The thicknesses of samples are $1.0 \mathrm{~mm}$ (sample A), $0.4 \mathrm{~mm}$ (sample E), and $1.2 \mathrm{~mm}$ (sample H). The solid line represents the corresponding fits. A shift in the base line was introduced to prevent overlap among the curves.

The sample was mounted in a computer-controlled translation stage to be scanned in the focus region along the beam propagation direction ( $Z$-axis). Negative values of $Z$ correspond to locations of the sample between the focusing lens and its focal plane. A photodetector with an adjustable aperture in front of it was placed in the far-field region. The aperture size with radius $r_{a}$ is related to the linear aperture transmittance by $S=\left[1-\exp \left(-2 r_{a}^{2} / w_{a}^{2}\right)\right]$, with $w_{a}$ denoting the beam radius at the aperture for very low incident power. A closed-aperture $Z$-scan experiment corresponds to $S<1$, which is employed for $n_{2}$ measurements, while $S=1$ is used for the determination of $\alpha_{2}$.

Figure 1 shows typical closed-aperture $Z$-scan traces for three samples measured at 1400, 1500, and $1600 \mathrm{~nm}$. The
TABLE II. Nonlinear refractive index for different laser wavelengths.

\begin{tabular}{cccccc}
\hline \hline & \multicolumn{5}{c}{$n_{2}\left(10^{-15} \mathrm{~cm}^{2} / \mathrm{W}\right)$} \\
\cline { 2 - 6 } Sample & $1400 \mathrm{~nm}$ & $1450 \mathrm{~nm}$ & $1500 \mathrm{~nm}$ & $1550 \mathrm{~nm}$ & $1600 \mathrm{~nm}$ \\
\hline A & $3.2 \pm 1.0$ & $3.1 \pm 0.9$ & $3.0 \pm 0.9$ & $4.1 \pm 1.2$ & $2.3 \pm 0.7$ \\
B & $1.7 \pm 0.5$ & $1.6 \pm 0.5$ & $2.1 \pm 0.6$ & $2.8 \pm 0.8$ & $2.5 \pm 0.7$ \\
C & $2.5 \pm 0.8$ & $2.4 \pm 0.7$ & $2.8 \pm 0.8$ & $3.1 \pm 0.9$ & $2.1 \pm 0.6$ \\
D & $1.8 \pm 0.5$ & $2.1 \pm 0.6$ & $2.3 \pm 0.7$ & $2.7 \pm 0.8$ & $1.8 \pm 0.5$ \\
E & $3.6 \pm 1.1$ & $3.6 \pm 1.1$ & $3.0 \pm 0.9$ & $2.8 \pm 0.8$ & $3.1 \pm 0.9$ \\
F & $3.2 \pm 0.9$ & $2.5 \pm 0.7$ & $3.2 \pm 0.9$ & $3.4 \pm 1.0$ & $3.9 \pm 1.2$ \\
G & $2.8 \pm 0.8$ & $3.7 \pm 1.0$ & $3.5 \pm 1.1$ & $4.4 \pm 1.3$ & $3.6 \pm 1.1$ \\
H & $2.4 \pm 0.7$ & $2.1 \pm 0.6$ & $3.7 \pm 1.1$ & $2.4 \pm 0.7$ & $2.6 \pm 0.8$ \\
\hline \hline
\end{tabular}

vertical axis plots the normalized transmission through the iris placed in the far-field region and the horizontal axis shows the distance scanned along the $Z$ axis. The behavior of the other samples is analogous to the ones illustrated by Fig. 1 with similar signal-to-noise ratio. A self-focusing nonlinearity $\left(n_{2}>0\right)$ is observed for all samples.

NL absorption was not observed that implies negligible two-photon absorption coefficients, smaller than the detection limit of the experimental setup $\left(\alpha_{2}<0.003 \mathrm{~cm} / \mathrm{GW}\right)$.

The experimental data were analyzed following the procedure of Ref. 11. The closed-aperture data was analyzed by fitting the normalized transmittance of the samples to $\Delta T$ $=0.406 k L_{\text {eff }} n_{2} I$, where $k=2 \pi / \lambda, L_{\text {eff }}=[1-\exp (-\alpha L)] / \alpha, L$ is the sample length, and $\lambda$ is the excitation light wavelength. The magnitude of $n_{2}$ was obtained by comparison with the value of fused quartz, $2.2 \times 10^{-16} \mathrm{~cm}^{2} / \mathrm{W},{ }^{12}$ that was used as a calibration standard. The measured values of $n_{2}$ obtained for laser intensity of $70 \mathrm{GW} / \mathrm{cm}^{2}$ are given in Table II for all samples. Errors of $\approx 30 \%$ are estimated to take into account the effects of pulse-to-pulse laser intensity fluctuations.

Referring to Table II one can notice that within the experimental errors there is no large dependence of the $n_{2}$ values with respect to the laser wavelength (neither to the samples' composition). This result can be understood considering that the wavelengths used are far from resonance with the samples' band gap. We recall that the previous measurements of the linear refractive indices ${ }^{4}$ have shown that their values at 633 and $1500 \mathrm{~nm}$ differ by less than 3\%. On the other hand, at $1550 \mathrm{~nm}$ the linear refractive index assumes values that differ by $\approx 5 \%$ for different samples compositions. These small variations imply that the NL refractive index would have values of the same order of magnitude according to the Miller's rule. ${ }^{13}$ Also the theoretical predictions based on a classical nonlinear oscillator [Boiling, Glass, and Owyoung (BGO) model] presented in Ref. 4 indicate small dispersion of $n_{2}$ in the range of wavelengths used in the present experiments.

The values of $W$ and $T$ were calculated considering the average values of $n_{2}$ and the value of $\alpha_{2}=0.003 \mathrm{~cm} / \mathrm{GW}$. Figure 2 shows the results for $1550 \mathrm{~nm}$. It can be seen that the samples present values of $W$ and $T$ that are very good with respect to the usual requirement for all-optical switching. The values obtained for all samples at wavelengths from 1400 to $1600 \mathrm{~nm}$ are in the range of $0.21<T<0.48$ and 

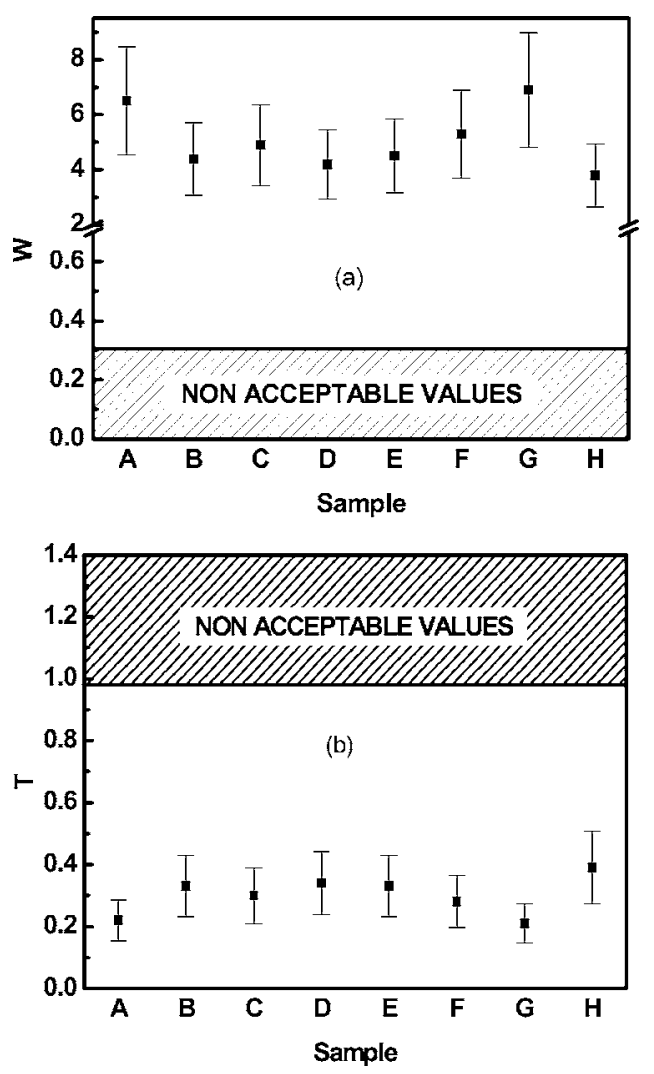

FIG. 2. Figure of merit for all-optical switching at $1550 \mathrm{~nm}$.

$3.8<W<11$. It is generally accepted that appropriate materials should present $T<1$ irrespective of the device and $W$ $>0.27$ for NL Fabry-Perot based devices. ${ }^{1}$ Therefore, from the data presented in Fig. 2, one can see that the antimony glasses compositions herein presented are very good choice for photonic devices.
In summary, the NL refractive indices of antimony glasses were determined for wavelengths from 1400 to $1600 \mathrm{~nm}$ and their performance for all-optical switching was evaluated with basis on the figures of merit. The results show that the glasses compositions studied in this work are very appropriate for ultrafast photonics at telecom wavelengths.

The financial support by the Brazilian agencies Conselho Nacional de Desenvolvimento Científico e Tecnológico (CNPq), Fundação de Amparo à Pesquisa do Estado de São Paulo (FAPESP), and Fundação de Amparo à Ciência e Tecnologia do Estado de Pernambuco (FACEPE) is acknowledged.

${ }^{1}$ G. E. Stegeman, in Nonlinear Optics of Organic Molecules and Polymers, edited by H. S. Nalva and S. Miyata (CRC, Boca Raton, Fl., 1997) p. 799.

${ }^{2}$ R. E. de Araújo, C. B. de Araújo, G. Poirier, M. Poulain, and Y. Messaddeq, Appl. Phys. Lett. 81, 4694 (2002).

${ }^{3}$ E. L. Falcão Filho, C. A. C. Bosco, G. S. Maciel, C. B. de Araújo, L. H. Acioli, M. Nalin, and Y. Messaddeq, Appl. Phys. Lett. 83, 1292 (2003). ${ }^{4}$ E. L. Falcão Filho, C. B. de Araújo, C. A. C. Bosco, G. S. Maciel, L. H. Acioli, M. Nalin, and Y. Messaddeq, J. Appl. Phys. 97, 013505 (2005).

${ }^{5}$ B. Dubois, H. Aomi, J. J. Videau, J. Portier, and P. Haggenmuller, Mater. Res. Bull. 19, 1317 (1984).

${ }^{6}$ B. Dubois, J. J. Videau, M. Couzi, and J. Portier, J. Non-Cryst. Solids 284, 177 (2001).

${ }^{7}$ M. M. Ahmed and D. Holland, Glass Technol. 28, 141 (1987).

${ }^{8}$ G. Poirier, M. Poulain, and M. Poulain, J. Non-Cryst. Solids 284, 117 (2001).

${ }^{9}$ M. Nalin, M. Poulain, S. J. L. Ribeiro, and Y. Messaddeq, J. Non-Cryst. Solids 284, 110 (2001).

${ }^{10}$ F. S. de Vicente, M. S. Li, M. Nalin, and Y. Messaddeq, J. Non-Cryst. Solids 330, 168 (2003).

${ }^{11}$ M. Sheik-Bahae, A. A. Said, T. Wei, D. J. Hagan, and E. W. Van Stryland, IEEE J. Quantum Electron. 26, 760 (1990).

${ }^{12}$ R. De Salvo, A. A. Said, D. J. Hagan, E. W. Van Stryland, and M. SheikBahae, IEEE J. Quantum Electron. 32, 13 (1996).

${ }^{13}$ Y. R. Shen, The Principles of Nonlinear Optics (Wiley, New York, 1984). 